\title{
Socialization and Proactive Behavior: Multilevel Exploration of Research Productivity Drivers in U.S. Business Schools
}

\author{
OLGA RYAZANOVA \\ PETER MCNAMARA \\ Maynooth University, County Kildare, Ireland
}

\begin{abstract}
We explore the joint relationship that organizational environment and individual proactive behavior have with the research performance of business school academics. We draw upon sociology of science research, "new careers" literature, and social capital research to build a multilevel model of individual research productivity emergence. The study looks at the interplay between organizational scripts and individual strategies as part of a microfoundations research program, and seeks to create consensus on the relative importance of each antecedent in supporting research outcomes. Our hypotheses are tested using a sample of 500 academics randomly selected from 25 research-intensive U.S. business schools ranked at the top of the University of Texas at Dallas ranking. The findings of the study demonstrate that both organizational environment and individual behavior influence the research performance of U.S. business school faculties, with collaboration behavior being the most important driver of research outcomes. These findings can inform decision making for academics at all stages of a research-active career. We hope that the developmental practices based on these results will become part of doctoral students' training and will facilitate the students' socialization into the research profession.
\end{abstract}

Business schools are both producers of researchers, through their $\mathrm{PhD}$ programs and faculty development activities, and consumers of researchers, through their hiring of new faculty members. The

\footnotetext{
We thank our Action Editor Lisa Burke-Smalley and three anonymous reviewers who have provided insightful comments that helped develop this paper for publication without stifling the original voice of the authors. The authors would also like to thank several graduate students who assisted with some aspects of the data collection process, namely, Peiran Su, Shane O'Connor, Gill Brennan, Peter Foster, Conor Foley, Edward Mackey, and Mark Wiley. We are also grateful to our colleagues Ciaran Heavey, Karan Sonpar, and Dorota Piaskowska who have offered advice on issues of method and sampling, and to both Gerry McNamara and Zeki Simsek for conceptual advice. We gratefully acknowledge partial financial support from the Innovation Policy Simulation for the Smart Economy project, which is funded under the Programme for Research in Third Level Institutions (PRTLI) cycle 5 and cofunded by the European Regional Development Fund.
}

capability of business schools to mentor a new generation of management scholars (doctoral students and early-stage hires) for sustainable research careers and to hire candidates with the highest research potential ought to be rooted in the deep understanding of factors that drive publication outcomes and scientific impact. Elite business schools are likely to possess this knowledge as a result of extensive experience; however, $\alpha$ broader and growing cohort of business schools that have joined the "publish-or-perish" game in recent decades may benefit from additional insights into the processes and behaviors underlying research productivity emergence. With this study, we seek to provide these insights which are instrumental in designing doctoral education programs and in shaping faculty selection and development practices. 
The current state of research on the antecedents of research performance is characterized by a divide between scholars who believe in the dominance of organizational factors and those who argue for the importance of proactive individual-level strategies. The former speak about a "handicap of initial identification with a less prestigious department" (Bedeion, Cavazos, Hunt, \& Jauch, 2010: 13). In their opinion, this has a permanent detrimental effect on academic productivity (Bedeion et al., 2010; Crone, 1965) due to the path-dependent nature of academic careers. The latter put forward networking and mobility as means to influence research productivity through proactive behavior at the later stages of career development (Baruch \& Hall, 2004). Those who see early-career organizational affiliation as being the main driver of research performance draw their arguments from sociological studies dating from 1950 to the 1980s (Coplow \& McGee, 2001; Clemente \& Sturgis, 1974). The arguments of the human-agencydriven view of individual performance are supported by evidence from the "new careers" literature and from social capital research (Baruch \& Hall, 2004; McFadyen \& Cannella, 2004; McFadyen, Semadeni, \& Cannella, 2009).

None of these perspectives alone can explain individual-research performance in a globalized business school industry. A path-dependence view does not account for the increased diversity of human capital or increased competitive pressures (Certo, Sirmon, \& Brymer, 2010). The "new careers" literature relies predominantly on conceptual and qualitative research (e.g., Baruch \& Hall, 2004; Richardson \& McKenna, 2003), which makes it difficult to understand the scope and significance of the theorized effects upon individual performance. The extensive social capital research literature (see e.g., Payne, Moore, Griffis, \& Autry, 2011) focuses on the role of networks in supporting research performance, without considering the embeddedness of individuals in social structures. One recent exception is the work of Seibert et al. (2014), which includes "PhD university reputation" and "current university reputation" in its analysis. They, however, include reputation as a control variable, maintaining the focus on the link between social networks and research. In another recent study, Judge et al. (2012) looked at the frequency of collaboration in conjunction with the academic pedigree of researchers as predictors of impact, but their social network analysis fails to explore the structure of coauthorship networks.

In our work here, we seek a consensus between a path-dependence perspective, which builds upon professional socialization as a key mechanism in researchers' careers, and a proactive perspective, which builds upon social-capital-related mechanisms of performance development. The "glue" that holds this view of research performance together is a multilevel framework that brings together organizational- and individual-level drivers of success in producing research. This fromework is grounded in the "new careers" literature (Dany, Louvel, \& Valette, 201 1; Duberley, Cohen, \& Mallon, 2006) and the microfoundations literature (Barney \& Felin, 2013; Coff \& Kryscynski, 2011). "New careers" scholars explore the interplay between individual and organizational factors in predicting individual-level correer outcomes, while microfoundations research, in a more general way, focuses on the links between the microand macrolevel drivers of organizational outcomes.

We seek to contribute to the development of doctoral programs in business schools by offering insights into the relationships between the career choices, publication practices, and outcomes of successful academics. We build upon the research productivity literature (e.g., Aguinis, de Bruin, Cunningham, Hall, Culpepper, \& Gottfredson, 2010; Seibert, Kacmar, Kraimer, Downes, \& Noble, 2014), extending it in several ways. First, our study goes beyond early-career organizational influences and the role of current affiliation to explore the role of career-long exposure to organizational scripts in the process of developing research productivity. Second, we explore the relationship of interorganizational and international mobility with individual research outcomes. Third, and most important, we measure the relative importance of organizational and individual factors in the careers of researchers.

Theoretically, we respond to the call from Barney and Felin (2013: 146), who argue that "we need comparative theories and associated empirical analysis that prioritizes different levels of analysis in terms of their respective contribution to overall performance." Such comparative analysis is at the core of this article. We view the emergence of research productivity in knowledge-intensive organizations (Coff \& Kryscynski, 2011; Ployhart \& Moliterno, 2011) as a consequence of interplay between organizational scripts and individual choices. Methodologically, we respond to the call for the wider use of multilevel designs in organizational studies (e.g., Breugst, Patzelt, Shepherd, \& Aguinis, 2012) by examining cross-level direct and interactive relationships between individual research performance and individual-organizational factors. 


\section{CONCEPTUAL BACKGROUND}

\section{Socialization As a Driver of Research Output}

\section{Path-Dependence Perspective}

Research productivity emergence starts with professional socialization, which is defined as "the process by which on individual acquires the values, expected behaviors, and social knowledge needed to assume an active role" in a given profession (Cable, Gino, \& Starts, 2013: 2). The socialization process is part of professional education and leads to the acquisition of symbolic, intellectual, and, to on extent, social capital, which are instrumental in an individual's future career (Vaara \& Faÿ, 201 l). In an academic context, professional socialization predominantly occurs as a part of doctoral education ( $\mathrm{Li}$ \& Seale, 2008; Stuart \& Ding, 2006) and includes the transmission and acquisition of discipline-specific skills (i.e., intellectual capital) and the awareness of professional norms (the "rules of the game"). "Like the elders of any tribe, academic elders pass on the wisdom and 'tricks' of the culture to the next generation" (Adler \& Harzing, 2009: 87).

In science, socialization during a doctoral program is considered the most common practice for honing the skills of would-be researchers (Baker \& Lattuca, 2010; Stuart \& Ding, 2006). The wider academic community can also play an active role in shaping future researchers' understanding of the profession. "It is through participation in the intellectual community in the field and the home institution that doctoral students build the knowledge and skills required for scholarship in their field of study" (Baker \& Lattuca, 2010: 809). The interaction between an author, a journal editor, and multiple reviewers, which leads to the first publication of an academic's work in a peer-reviewed journal, is a formative experience in the development of a future publishing career. In sum, the environment of the doctoral program and the first publishing experience provide intellectual capital that lays the foundation for an academic's ability to produce research in the form of journal publications.

As evidenced by multiple studies conducted into the role of academic origin in the development of scientific productivity, the research-intensiveness of the starting point in scientists' careers has a longterm impact on their ability to produce original

\footnotetext{
${ }^{1}$ This "internalized system of schemes for perceiving, thinking, feeling, and acting within a given field and its structures" was called habitus by French sociologist of education Pierre Bourdieu (Vaara \& Faÿ, 2011: 30).
}

research (for a review of these works, see, e.g., Clemente \& Sturgis, 1974). First, highly productive faculty members possess a large stock of disciplinespecific knowledge, which they can transfer to doctoral students, thus establishing a foundation of their students' research productivity. Second, career research argues that the research-intensiveness of academic origin facilitates access to productive workplaces by providing symbolic capital, which serves as a proxy for the potential quality of a future researcher (Bedeion et al., 2010; Miller et al., 2005). When academics have succeeded in publishing before graduation, this reduces uncertainty in the hiring process and provides some proof that they have the skills required to produce research (Mangematin \& Baden-Fuller, 2008). In such cases, potential research productivity is assessed through an evaluation of the $\mathrm{PhD}$ institution's research output and of the quality of the outlet in which the work was published-the strength of the latter would compensate for the weakness of the former (Bonnal \& Giret, 2009).

A favorable assessment of an academic's symbolic and intellectual capital allows access to research-intensive institutions that provide both the resources and motivation necessary for achieving high research performance. In such institutions, the faculty works side by side with colleagues who have survived the process of what D'Aveni (1996) calls "input creaming" (i.e., a stringent selection of the best candidates from the large population of applicants willing to work in a top organization) and have demonstrated the ability to publish at the high level required in elite schools. These colleagues become both role models and sources of further socialization into the research profession. Moreover, a researchfriendly environment, characterized by lower teaching loads and generous research funding, is propitious to delivering scientific outcomes (Crone, 1965; Long, Bowers, Barnett, \& White, 1998; White, James, Burke, \& Allen, 2011) and motivates the faculty to prioritize activities leading to publications. Consequently, research productivity is developing through a self-reinforcing mechanism of accumulative advantage, which leads to increasing rigidity in an academic career path (Stephan, 1996). These path-dependent mechonisms indicate the overorching importance of an early-career stock of intellectual and symbolic capital as an antecedent of research productivity. Thus,

Hypothesis la: The research-intensiveness of academic origin is positively associated with long-term research productivity. 
Although arguments for the path-dependence perspective seem plausible, recent academic careers research provides evidence of a less-linear trajectory of mobility across academic workplaces. Both the lack of tenure-track positions in researchintensive universities (Huisman, de Weert, \& Bartelse, 2002) and factors rooted in the individual characteristics of academics, such as family commitments and the pursuit of new experiences (Richardson \& McKenna, 2003), lead to higher diversity of workplaces. Studies in the sociology of science (e.g., Long \& McGinnis, 1981) have demonstrated that the research-intensiveness of an immediate organizational environment (measured by a school's standing in research-based rankings) has a strong impact upon the research performance of individual academics (see e.g., Albrecht, Thompson, \& Hoopes, 2011; Smith, Fox, Pork, \& Lee, 2008 for more recent evidence supporting this argument). This impact results from exposure to organizational scripts and to the organizational stock of intellectual capital. It is important, therefore, to explore the influence of professional socialization post-PhD rather than to assume the similarity of these scripts to the script provided by the PhD school. A combination of generosity of resources, quality of academic peers, and organizational incentives is likely to lead to a positive association between employment in more productive organizations and higher individual research performances of forculty members.

Unlike numerous studies that examine current affiliation as a driver of research performance (e.g., Chan, Chen, \& Fung, 2009; Cruz-Castro \& SanzMenendez, 2010; Long et al., 1998), we believe it is important to explore individuals' entire career histories to understand the impact of post- $\mathrm{PhD}$ socialization. Therefore, we look at all post-PhD workplaces as sources of intellectual and symbolic capital, and assume that:

Hypothesis 1b: The research-intensiveness of post- $P h D$ workplaces is positively associated with long-term research productivity.

\section{Social Capital As a Driver of Research Output}

\section{Proactive Behavior Perspective}

Following the increased globalization of the business school industry in the 1990s, several new trends have begun to influence the individual performance of academics. First, the expansion of the AACSB across the borders of the United States and the emergence of EQUIS as another international accreditation body (Durand \& McGuire, 2005) have brought new "publish-or-perish" pressures to a wide range of organizations outside North America. The pressure from global accreditation bodies has been reinforced by pressures from government stakeholders (e.g., through the Research Assessment Exercise in the U.K.), which have made university funding dependent on research output. The calls for increased efficiency and accountability in higher education have directed researchers toward highly visible international journals (Sousa, de Nijs, \& Hendricks, 2010). The resulting increase in competition for space in the top journals has made it more difficult to publish research in these outlets (Certo et al., 2010), led to more stringent requirements for scientific rigor (Ashkanasy, 2010), and may have had an impact upon both space available in and standards of mid-and lower tier journals. Despite the emergence of some new journals, the limited time that business school academics have for research increases their reliance on journal "impact factors" to navigate the field (Judge, Cable, Colbert, \& Rynes, 2007). The resulting, disproportionate importance placed upon publishing in the top journals leads to rejection rates of up to $97 \%$ of all submitted manuscripts (Day, 2011). Although this figure may seem extreme, it is not for from the general level of rejections for the majority of top journals. In a recent editorial, Jones and Gatrell (2014) reported that only 24 of 300 submissions are published annually in the International Journal of Monagement Reviews, or a rejection rate of $92 \%$. The same rejection rate is cited by the editor of the Journal of Organizational Behavior (Ashkanasy, 2010), where only around 50 of more than 600 submissions are accepted for publication. This is a dramatic change from the acceptance rate "in excess of 70 percent" for scientific journals, as reported by Paula Stephan 2 decades ago (Stephan, 1996: 1216).

Second, academia has mirrored other industries in the deterioration of a secure and stable career model. The proportion of part-time faculty members and faculty members outside tenure tracks has increased as a result of the accreditation and efficiency pressures discussed above (Callie \& Cheslock, 2008; Huisman et al., 2002). Academic career scholars disagree in their reaction to this trend. Some have met the "boundaryless careers" model with enthusiasm and argue that proactively driven careers are the future of empowered human capital (e.g., Baruch \& Hall, 2004). Others are cautious and emphasized issues with the increased power of organizations over employees 
in the age of scarce job security (Dany, 2003). The more optimistic fraction of the "new careers" field presents an individual as a proactive creator his or her own career across multiple organizations. The pessimistic fraction argues that proactiveness is used by individuals to manage the increased difficulty in meeting organizational performance standards and does not challenge the dominant role of organizational scripts.

\section{Collaboration Behavior: Leveraging the Networks}

"New careers" scholars generally agree that networking and mobility serve as proactive mechanisms supporting individual performance. For instance, recent research on proactive (or self-directed) careers outlines "career planning, skill development, and networking as fundamental proactive career behaviors" (Taber \& Blankemeyer, 2015: 86; see also Hirschi, Freund, \& Herrmann, 2014). ${ }^{2}$ Prior research has demonstrated that social capital embedded in collaboration networks may be used to improve individual performance in general, and research performance in particular (McFadyen \& Cannella, 2004; Seibert et al., 2014; Stephan, 1996). Collaboration allows researchers to take part in several projects simultaneously, sharing the work between members of each research team. Coauthorship provides access to a more diverse stock of knowledge and allows researchers to examine phenomena from different angles. Coauthorship networks ${ }^{3}$ can perform the function of a sounding board at the early stage of idea development, act as a friendly reviewer at the manuscript drafting stage, and be a source of tacit journal-related knowledge at the submission stage. After the publication of a study, a coauthorship network plays a role in knowledge dissemination, as more researchers advocate the value of a particular project.

The size of a coauthorship network is a proxy for the potential stock of information available to an academic and the number of individuals likely to contribute to knowledge dissemination. Actual research support within a coauthorship network can

\footnotetext{
${ }^{2}$ We explore individual behaviors rather than psychological traits of proactive individuals, which are examined elsewhere in career literature (e.g. White et al., 2011; Seibert, Crant, \& Kraimer, 1999). Thus, the proactive mechanisms that we discuss are proxies for individual attributes examined in research on self-directed careers.

${ }^{3}$ We understand a coauthorship network to be the ego-network of an academic, including all of her coauthors.
}

be measured by the strength of coauthorship ties, or the frequency with which an individual collaborates with the same coauthor (McFadyen et al., 2009; Seibert et al., 2014). Repeated collaboration increases trust between coauthors, making creative processes smoother. This may lead to higher research output, as trust is positively related to task performance (Colquitt, Scott, \& LePine, 2007). Repeated collaboration may be a signal of a good fit between coauthors and of the complementarity of their knowledge, skills, and personal characteristics, which are beneficial for research productivity (Gonzalez-Brambila, Veloso, \& Krackhordt, 2013).

The size of a network and the strength of ties in it represent different dimensions of social capital. We therefore might expect that they would reinforce each other. Given the complexity of the collaborative research process, which requires a high level of understanding and trust between coauthors, we argue that a large coauthorship network that contains stronger relationships between coauthors will lead to higher research output. Such a network, which is closer to the bonding network type (Lee, 2009: 250), ${ }^{4}$ ought to combine broad access to information with trust and "mutual empowerment" of the coauthors. Thus, where the collaboration behavior of an academic includes both the expansion of a network and a repeated partnership with coauthors within this network, we assume that:

Hypothesis 2: There is a positive relationship between collaboration behavior and research productivity.

\section{Interorganizational Mobility: "New Careers" Addition to the Proactive Behavior Toolbox}

Academic mobility is often considered to be instrumental in academic career development (Sabatier, Carrere, \& Mangematin, 2006; Zubieta, 2009). Mobility between workplaces increases diversity of experience, facilitating the development of professional skills and the broadening of researchers' perspectives. The exact nature of the relationship between prior experience and performance, however, remains underexplored. Dokko, Wilk, and Rothbard (2009) demonstrate that while prior taskrelated experience contributes to the development

\footnotetext{
${ }^{4}$ The opposite of this type of network is a bridging network, which includes a large number of heterogeneous weak ties and has the benefit of providing access to diverse information.
} 
of knowledge and skills, it may negatively influence performance if employees experience difficulties adjusting to the culture of a new workplace. Dietz and Bozeman (2005) found that academics' mobility between universities and industry $R \& D$ centers had a negative effect on research productivity; they explained this finding by the fact that there are fewer incentives for publishing in industrial $R \& D$. At the same time, research on academic inbreeding shows a negative relationship between a lack of academic mobility and research productivity (CruzCastro \& Sanz-Menendez, 2010; Horta, Veloso, \& Grediaga, 2010).

Current research on academic mobility as a predictor of research productivity is, however, mostly limited by the study of postdoctoral mobility (e.g., Cruz-Castro \& Sanz-Menendez, 2010; Zubieta, 2009) and the academic inbreeding phenomenon (CruzCastro \& Sanz-Menendez, 2010; Horta et al., 2010). Postdoctoral mobility is not as widespread in the career model of business school faculties as it is in life sciences and other STEM disciplines. The studies of inbreeding offer limited insight into the process of intellectual and social capital acquisition due to the binary nature of the explored variable and its focus on the initial placement stage of academic careers. We take a more in-depth approach to measuring mobility and argue that in the case of career mobility between academic institutions, the accumulation of experience will lead to increased research productivity:

Hypothesis 3a: Prior academic experience (number of workplaces) within the United States is positively related to research productivity.

International mobility may become a driver of cross-cultural knowledge acquisition, bring financial rewards, and facilitate the development of professional networks (Jepsen et al., 2014; Richardson \& McKenna, 2003; Richardson \& Zikic, 2007). Mobility may also be stressful due to the loss of connections with friends and family, difficulties in spouses finding employment, visa and language barriers, and the general emotional toll of "living out of a suitcase" (Richardson \& Zikic, 2007: 173). These qualitative insights help to understand the consequences of mobility. Existing research on international mobility does not address directly the relationship between mobility-related factors and research performance. Hence, there is a need for quantitative exploration of this relationship in a business school setting.
All academics in the sample explored here are located in the United States. Consequently, we are interested in distinguishing between the impact of mobility within the U.S. system, which allows the development of professional relationships and the dissemination of knowledge without the hurdles of international relocation, and the impact of mobility outside the United States. Although mobility outside the United States has a substantial cost associated with a greater change in cultural environment, educational and legal regulations, and practices, it may also be more rewarding due to higher exposure to different research perspectives.

Hypothesis 3b: Prior academic experience (number of workplaces) outside the United States is positively related to research productivity.

Academic mobility may bring more value to academics with a lower quality of professional socialization, if they lack early-career access to skills, knowledge, and role models. Mobility, and in particular international mobility, makes it hard for the graduates of top-ranked schools to maintain contact with coauthorship networks established early in their careers. Social networks research emphasizes spatial proximity as a key driver of networking (Brass, Galaskiewicz, Greve, \& Tsai, 2004). While modern communication technologies have facilitated collaboration to some extent, a recent survey of scientists conducted by the National Bureau of Economic Research (NBER) demonstrated that the exchange of emails or Skype calls still fails to fully replace face-to-face research conversations (Freeman, Ganguli, \& Murciano-Goroff, 2014). Email communication lacks important nonverbal cues that we usually pick up from tone of voice or body language (Epley \& Kruger, 2005; Kruger, Epley, Parker, \& Ng, 2005). The study of two distributed research teams by Vasileiadou and Vliegenthart (2009: 1266) revealed that email communication "cannot substitute for the important role meetings play in research productivity."

Skype communication offers some degree of visual interaction (subject to technology working properly). However, it lacks any spontaneity: For instance, you cannot usually go for a stroll in the park with your conversation partner while simultaneously staying in front of a screen where a camera can capture your image. Moreover, seemingly minor technical problems, such as sound delays or the need to talk more loudly and articulately than one usually does, may be surprisingly disruptive for the 
free flow of conversation. Last, Skype conversations may be difficult to schedule where collaborators are located in different time zones: For example, when it is 9 a.m. in Washington, DC, it is 9 p.m. in Beijing, so work hours for coauthors located in the two different cities would be completely out of sync. Thus, we expect the positive association of mobility with research outcomes to be less pronounced for academics with a high quality of professional socialization, who may lose important connections after moving away from their initial network.

Hypothesis 4: The research-intensiveness of academic origin will moderate the relationship between prior academic experience and research productivity such that as research-intensiveness increases, the relationship between prior academic experience and research productivity will become weoker.

The conceptual model is summarized in Figure 1.

\section{Importance of Comparative Analysis}

\section{Which Level Contributes More?}

In designing doctoral programs and selecting potential $\mathrm{PhD}$ students, it is important to understand the relative importance of formative environments and proactive behavior in developing the ability of future faculty members to produce research. This can help create adequate career expectations among graduates and support them in accumulating those types of human capital that are most likely to contribute to their future research performance.

The relative importance of organizational and individual factors to research productivity also has an impact on the mind-set with which hiring committees should approach the selection of candidates in research-active schools. If as a result of our investigation it turns out that organizational factors, that is, symbolic capital and intellectual capital, are significantly more important, the emphasis in the selection process ought to be on early anchoring in the research-intensive institution as a life-long driver of research performance. In this case, given the expansion of the business school industry, it becomes vital to understand the boundaries of the worldwide strata of research-intensive institutions to be able to increase the pool of potential candidates by hiring international faculty members with adequate research capabilities. Studies dedicated to the mapping and comparative analysis of research performance are instrumental in this task (e.g., Albrecht et al., 2011; Podsakoff, MacKenzie, Podsakoff, \& Bachrach, 2008). However, this approach to hiring has a negative side effect: It is known to reinforce existing "input creaming" processes in top schools (D'Aveni, 1996) and lead to "social closure" (Burris, 2004). Candidates with lower ranked or nontraditional educational backgrounds may be denied the opportunity to flourish in a research-intensive environment on the basis of the belief that they will not catch up with their peers, who started their research journeys within higher strata of research institutions.

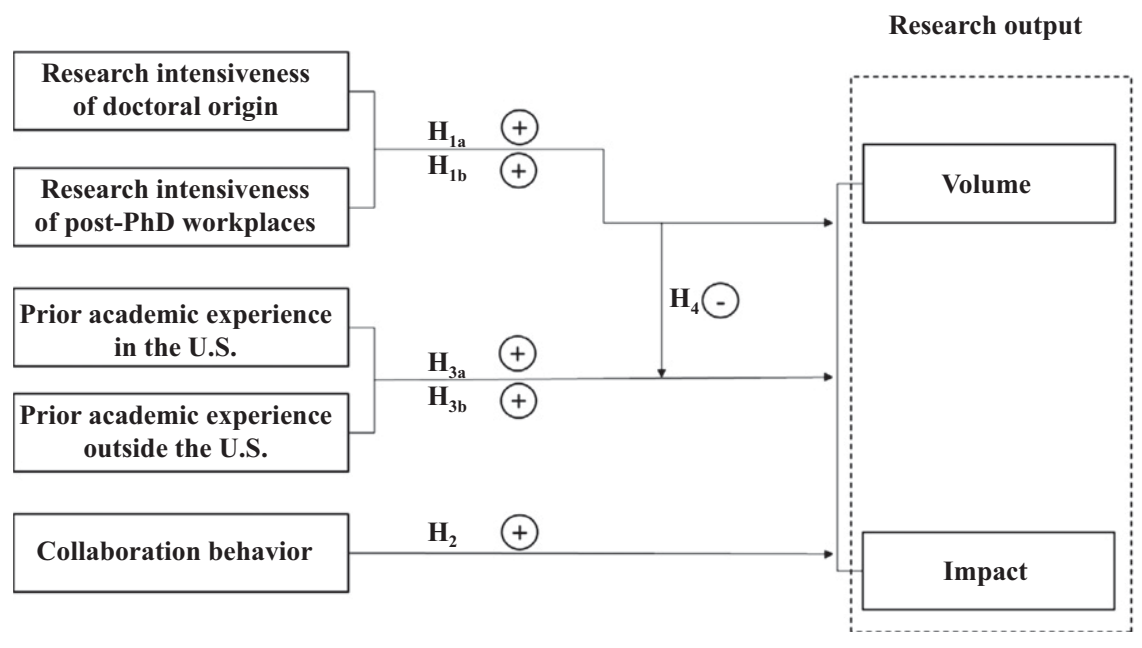

FIGURE 1

Conceptual Model 
If individual behaviors, that is, the building of social capital through collaboration and mobility, are more important in explaining variance in research performance, research productivity would to some extent be a result of agency-driven processes, where a motivation to excel in science leads to the proactive acquisition of knowledge resources (directly and through coauthors). Thus, for hiring committees, the key tork would become identifying the candidates capable of such proactive behaviors, and, later, ensuring that these behaviors were supported through organizational practices. Literature on the psychological foundations of proactive careers (e.g., Taber \& Blankemeyer, 2015; Hirschi et al., 2014) and literature on the antecedents of collaboration (e.g., Bevelander \& Page, 2011; Bozeman \& Gaughan, 2011) can offer valuable insights here, as well as the literature on academic mobility (e.g., Jepsen et al., 2014; Ng, Sorensen, Eby, \& Feldman, 2007).

Employee selection is just one step in ensuring that business school faculty members are researchactive. Organizational practices that seek to support and develop research productivity need to be informed by the understanding of the factors that contribute the most to vorionce in research performance. This could assist administrators in business schools in designing the processes that enable the emergence of a strategic human copital resource, that is, a research-active forculty member (Ployhart \& Moliterno, 2011).

\section{METHOD}

We construct an individual-level theory using multilevel analysis of individual- and organizationallevel data. A number of scholars have advocated the use of multilevel studies for the analysis of nested data to determine boundary conditions in organizational science through the exploration of cross-level effects and cross-level interactions, the interactions between higher and lower level variables (Breugst et al., 2012; Payne et al., 2011). This points toward multilevel analysis as an appropriate methodological foundation for microfoundations research.

\section{Sample}

In the first step of our sampling procedure, we needed to identify schools that provide strong motivation for their faculties to produce research in the form of journal publications. Using the University of Texas at Dallas (UTD) North American ranking as an established regional ranking of research-intensive business schools, we randomly selected 25 schools from the top-50 U.S. schools in the UTD ranking for the year $2011 .{ }^{5}$ Only U.S. schools were included to avoid potential bias due to country-level differences in academic career models. The UTD ranking is based on publications in 24 highly visible journals, which somewhat limits its validity as a measure of research-intensiveness for the entire business school industry, where academics publish in hundreds of peer-reviewed journals. To assess the extent of this limitation, we compared the UTD rank of our selected schools with their rankings based on publications in Financial Times 45 (FT45) journals and in 45 High Impact Journals (both rankings produced by Linton, 2012). The comparison revealed that $92 \%$ of our sample (all the schools except Baruch College and the University of California at Irvine) are ranked among the top-50 U.S. business schools by all three rankings. Thus, although the use of the UTD ranking is not a perfect solution, the results are reasonably robust to the deficiency of this measure of research-intensiveness.

In the second step, we randomly sampled 20 tenured academics from each school, maintaining the gender distribution inherent to each school. The sample size of 500 academics represents a compromise between having sufficient statistical power in the model and offering an insight into both organizational and individual drivers of research outcomes. The summary of the sample is presented in Table 1.

Starting from undergraduate education, information on career history was collected from resumes (available on business schools' websites) and from Hasselback's (2014) directory of faculty. Resumes have proved to be a useful source of career data in prior academic career studies (Dietz \& Bozeman, 2005). Hasselback's directories have also been used in the past to get career data for U.S. academics (Boyd, Finkelstein, \& Gove, 2005). Publication data for the entire span of an academic's career up to spring 2014 was retrieved from Thomson Reuters ISI Web of Science. Coauthorship data were extracted from this bibliometric data. Where data on doctoral education was unavailable in resumes, we used data from the ProQuest Database of Dissertations. We made occasional use of profiles from the social network LinkedIn to fill in missing categories of resume data. LinkedIn profiles are similar to resumes in that they are a self-reported record of a person's prior experience.

\footnotetext{
${ }^{5}$ After the exclusion of Canadian business schools from the sampling frame, the resulting top 50 US business schools are located between the positions 1 to 55 in the UTD ranking.
} 
TABLE 1

Sample Summary

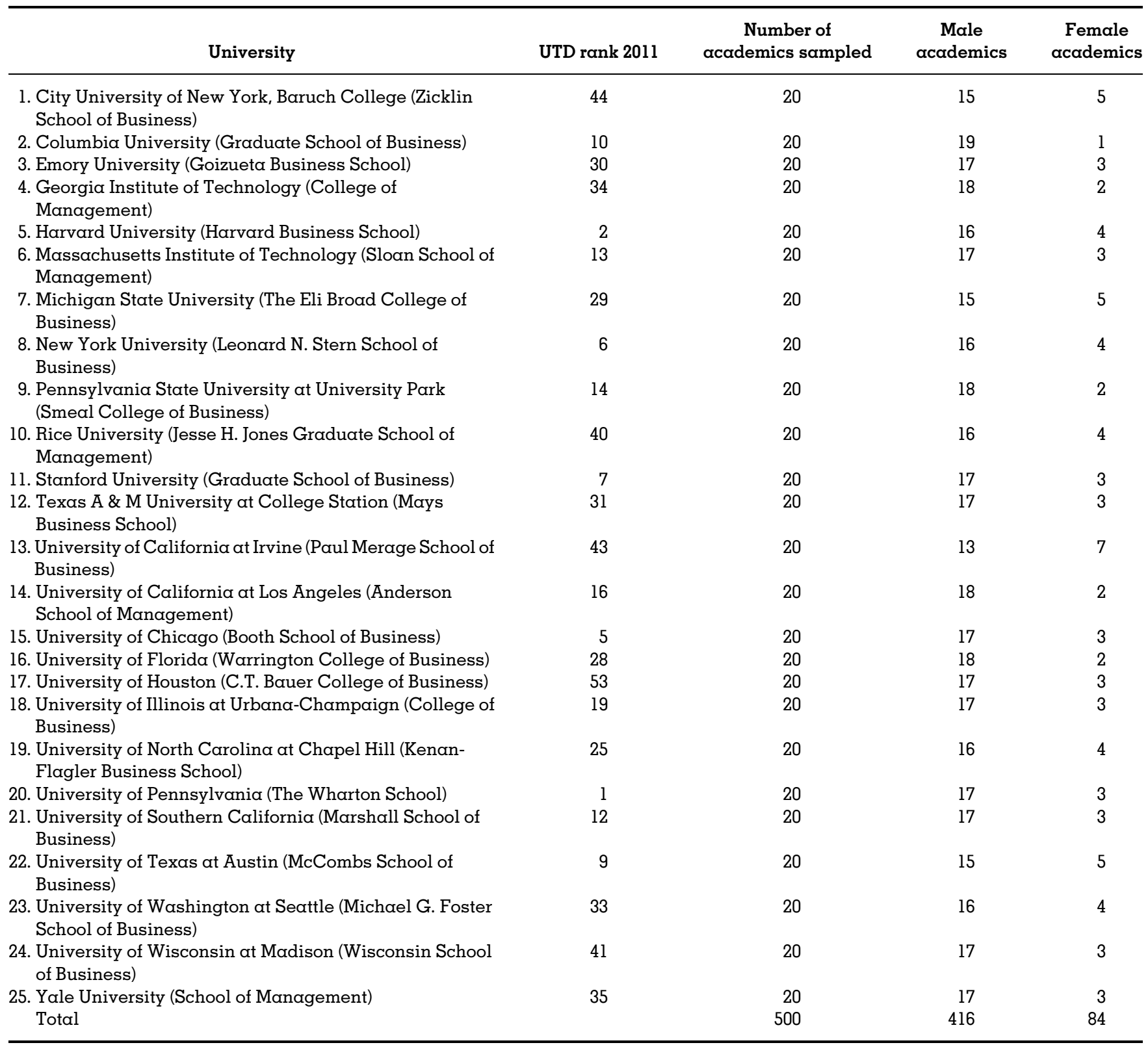

\section{Variables}

\section{Dependent Variable}

We were interested in exploring both the volume of research output and the scholorly impact of published research. Adhering to the general guidelines for the use of bibliometrics to assess research performance (Thomson Reuters, 2008), we decided to perform the analysis using multiple measures of research performance as a dependent variable before comparing the results to see if they were congruent. This is consistent with the approach taken by previous studies (e.g., Podsakoff et al., 2008). We used the number of papers published in peer-reviewed journals and proceedings (including book chapters ${ }^{6}$ ) as a measure of the volume of research, restricting them to publications visible on the ISI Web of Science database, and we used "total

\footnotetext{
${ }^{6}$ To make sure that the presence of book chapters did not influence the results of our analysis, we performed robustness tests, eliminating these from the study. No significant changes were observed.
} 
citation count" as a measure of total scholarly impact. We then adjusted the number of publications by the number of coauthors involved in each paper and by the professional age of each academic (years since $\mathrm{PhD}$ completion). The adjustment for coauthorship (i.e., fractional count) is recommended by prior studies (e.g., Judge, Weber, \& Muller-Kahle, 2012; Stephan \& Levin, 1991) as a better way to measure individual input into the production of research. Our data allowed us to address the limitation of Judge et al.'s study (2012) by calculating the exact number of coauthors for each paper. The adjustment by year allows us to compare the research productivity of academics who have spent different numbers of years in the profession (Smith et al., 2008). The number of citations was adjusted by coauthorship and the lifespan of each paper.

Both dependent variables displayed a nonnormal distribution, as confirmed by the Shapiro-Wilk test $(p<0.001)$ and Levene's Variance Homogeneity test. To manage this issue, we followed in the footsteps of previous researchers and log-transformed the numbers of papers and citations (Cruz-Castro \& Sanz-Menendez, 2010; Podsakoff et al., 2008).

\section{Independent Variables}

We used two measures to assess the researchintensiveness of an organizational environment that provides the symbolic and intellectual capital necessary for the development of research productivity. First, we used the UTD rankings to rank the institutions from which the sampled academics received their PhD degrees. UTD North American rankings were used for U.S. and Canadian schools; UTD World rankings were used for all other schools. All academics in the sample started their careers in different years; to address this issue, we calculated mean UTD rankings based on the data from 2000 (the earliest available) to 2011 (the start of data collection). The use of mean rankings is the best approximation we can achieve. We recognize that the data for 2000-2011 may not capture the earlier fluctuations of the rankings. Following prior research (e.g., Hall, Mairesse, \& Turner, 2007), we used PhD from top-10 schools in the UTD ranking (dummy) as a measure of the research-intensiveness of the PhDs. Power law distribution, observed by scholars who have studied research performance (e.g., Aguinis, O'Boyle, Gonzalez-Mule, \& Joo, 2016), means that a small number of high performers contribute disproportionately to overall research output within the field. In another study that we conducted recently, we analyzed publications in the 150 top
ISI-listed journals between 2007 and 2012 and found that the top-10 business schools produce $10 \%$ of all global research output, which is higher than the next 10 schools in the ranking (the schools ranked between 11th and 20th place contribute another $7 \%$ of global output). Although we do not claim that other schools do not produce research, we believe the high research-intensiveness of the top-10 schools may have a disproportionally strong influence on the development of research productivity.

Second, as discussed above, one's first publishing experience can also become a source of symbolic and intellectual capital. Symbolic capital from an academic's first publication was measured by the quality of the journal in which the paper was published. We chose citation measurement as the tool with which to assess this variable, as doing so allowed consistency to be maintained. We took the ISI 5 -year impact factor (from the Journal Citation report 2011) as the measure of peer-reviewed journal rank, recognizing that this choice entails the same potential limitation for the papers published prior to 2006.

Intellectual capital from first publication was measured by looking at the time before the first publication appeared in an ISI-visible journal. Precocity of publication is a signal of emphasis on research within $\alpha \mathrm{PhD}$ program and a sign of a school's ability to motivate and support students in producing publishable research. This variable is measured as the difference between the year of first publication and the year of $\mathrm{PhD}$ completion.

Third, we were interested in the influence of organizational scripts that academics experience in their post-PhD careers. To capture this antecedent of research productivity, we introduced a weighted rank of all workplaces variable, which reflects the research-intensiveness of post-PhD workplaces. The variable was measured as a sum of the UTD research ranks of all post- $\mathrm{PhD}$ institutions, weighted by the proportion of time an academic spent working for each institution. This variable was split into on 11-point scale by dividing the UTD ranking into 10 groups of 10 schools and adding the 1lth group, which contained the nonronked institutions. For ease of interpretation, the scale was reverse-coded, so that schools with UTD ranks 1-10 belong to the 1lth scale, and the schools not ranked by UTD belong to the lst scale. Again, the use of the UTD rank as a measure of research-intensiveness has its limitations if academics publish outside of the 24 journals underlying this ranking. However, the correlations of the UTD rank with the FT45 rank and the High Impact 45 rank (Linton, 2012) are 0.82 and 0.59, 
respectively, which points to the fact that the population of highly visible journals is reasonably well captured by this measure. Prior research demonstrated that academics in the most productive research institutions tend to torget highly visible journals (Seibert et al., 2014), which further reduces potential bias from the use of the UTD rank as a measure of institutional research-intensiveness. Still, there is a possibility that an institution that scores low in the UTD ranking may be a highly productive institution which targets low-ranked journals, and we accept this as a limitation of our research design.

Collaboration behavior was measured by multiplying the number of unique coauthors with whom an individual published research by the proportion of strong ties in this ego-network, that is, the percentage of coauthors with whom an academic has collaborated more than once. ${ }^{7}$ Prior academic experience (i.e., mobility in post-PhD careers) was measured by counting workplaces (including $\mathrm{PhD}$ school) throughout academic careers, and distinguishing between U.S. and non- U.S. institutions.

\section{Control Variables}

The control variable gender was included to capture the possible differences between the career histories of male and female academics. We further introduced the control variable cohort to account for the changes in the field (e.g., the increased competition). Academics in our sample completed their $\mathrm{PhDs}$ between 6 and 60 years prior to data collection. The variable was coded from 1 (up to 10 years before 2014 ) to 6 (51-60 years before 2014). Previous studies have also indicated that the degree of competition for the space in high-quality journals differs between discipline areas in organizational science, and that this has a direct impact upon academic productivity (Certo et al., 2010; Podsakoff et al., 2008). To capture this phenomenon, we introduced discipline area as a control variable. Three coders independently assigned a discipline on the basis of resume and publication data (average intercoder agreement icc $_{\text {avg }}=0.95$ ). The differences were discussed between coders, so that a consensus could be reached for each case. Sampled academics were allocated to one of the following discipline areas:

\footnotetext{
${ }^{7}$ We have performed robustness tests, defining strong ties as coauthors with whom an academic collaborated (1) more than three times, and (2) more than four times. These tests demonstrated that the relationship between this variable and the outcome variables does not depend on the measurement choice.
}

accounting, economics, finance, management information systems (MIS), management, marketing, organizational behavior/HR/education, operations research/logistics, and strategy.

\section{Data Analysis}

Due to the multilevel nature of the study, we used a multilevel mixed modeling (MLM) approach in STATA 13 software to analyze cross-level and samelevel relationships (Bliese, 2002; Breugst et al., 2012). Unlike those used in most multilevel studies, the dataset in this paper was not designed around a specific group structure. The nested structure of the data emerged instead due to the fact that we included both organizational-level and individuallevel predictors of individual performance here. Given the long-term nature of the phenomena explored, retrospective exploration of faculty members' career paths seemed to be a more appropriate research approach than the experimental designs used in many multilevel studies (e.g., Breugst et al., 2012).

"New careers" literature argues that individual agency is constrained by organizational scripts (Dany et al., 2011). Thus, it was appropriate that individual data were grouped according to the scale of an organizational-level variable. Five-hundred individuals in the sample were divided into 11 groups, based on the weighed rank of their workplaces, with an unequal number of actors in each. All variables were group-mean centered-a recommended method of centering when the output variable in multilevel research is situated on a lower level of analysis (Dalal \& Zickor, 2012). This means that all centered voriables represent the extent to which each observation is different from the within-cluster mean, where the cluster is defined as academics with the same average rank of workplaces.

The MLM approach is appropriate for obtaining correct estimates of relationships between variables in nested datasets and for measuring the share of intergroup variance. It is, however, less suitable for detailed comparative analysis of each variable's contribution to the explanation of variance in outcomes, due to the absence of standardized effect sizes. To estimate the relative contribution of organizational-level variables and individual-level variables to the explanation of variance in research performance, we used standardized ordinary least squares (OLS) analysis. Use of cross-sectional datasets to analyze the careers of academics has been a common approach as has the use of OLS to analyze this data (see specifically, Buchmueller, Dominitz, \& 
Hansen 1999; Carayol \& Matt, 2006). To ensure that this method could be used in our study, we tested the models using MLM and standardized OLS and compared the findings. The results were consistent. The sign and the significance of all relationships were the same, with one exception: the interaction between a top-10 PhD and prior experience in the United States is not significont in the MLM model explaining the impact of research, but is significant $(p<0.1)$ in the same OLS model. Because interactions were not included in our comparative analysis, we felt it appropriate to use standardized OLS. Following the conceptual logic of the study, we compare the base model, which includes control variables, with models that include organizational-level covariates only, individual-level covariates only, and both sets of predictors.

\section{Addressing Unobserved Heterogeneity Issues in the Sample}

There was a possibility that the retrospective exploration of business school faculty performance might be affected by self-selection among academics in the early stages of their careers. For instance, the choice of top-ranked $\mathrm{PhD}$ programs might be influenced by the superior abilities of students, which will eventually manifest as superior scholarly ability and higher research productivity. To take account of endogeneity in this study, we used Heckman's 2-step procedure as recommended in previous studies (Hamilton \& Nickerson, 2003). We collected additional data about the pre- $\mathrm{PhD}$ educational history of academics in the sample to introduce several instrumental variables. The results of our analysis show that self-selection into the top$10 \mathrm{PhD}$ programs is not present in our sample. The inverse Mills ratio is not significant in any of the models, and its inclusion in the corrected model does not change either the sign or the significance of the rank of $\mathrm{PhD}$. The details of this analysis are available from the authors upon request.

\section{RESULTS}

Academics in our sample had published an average of 20 ISI-visible papers (median $=15$ ) and accumulated 834 citations each over the course of their careers (median $=367$ ). When adjusted for coauthorship and time, this results in the mean volume of 0.4 papers per year and the mean impact of 29 (median $=15$ ) cites per year. The descriptive statistics for the other variables are provided in Table 2.
Several features of the dataset are worth particular notice. First, the positive correlation between $\mathrm{PhDs}$ from the top-10 schools and the weighted rank of workplaces confirms the path-dependent perspective; graduates of more research-intensive schools on average spend their careers in more research-intensive schools. Second, the negative correlation between the rank of the $\mathrm{PhD}$ and the size of the coauthorship network supports the assumption that academics use collaboration to compensate for a lower quality of early-career socialization. Third, the positive correlation between prior academic experience in the United States and the size of coauthorship networks provides tentative support to the idea that mobility is associated with the accumulation of social capital.

The results of the multilevel mixed modeling analysis for number of papers (the volume of research) are presented in Table 3. The calculation of ICC from the base model (Model 1 ) indicates that $4 \%$ of variance in volume of research can be attributed to the average research-intensiveness of the organizational environment where an academic spent her career. This provides support to Hypothesis lb, which looked at the impact of post-PhD socialization. Model 2 tests for the influence of organizational environments on the volume of research. Hypothesis la, which assumed positive association between the research-intensiveness of the doctoral origin and research productivity, received partial support. Early publishing and a $\mathrm{PhD}$ from a top-ranked school are positively related to the volume of research, but the impact factor of the first journal article is negatively related to such volume.

Model 3 added the individual-level proactive behaviors of collaboration and mobility as the antecedents complementary to organizational-level predictors of productivity. Hypothesis 2 is supported, as collaboration behavior is positively related to the volume of research. Hypotheses $3 a$ and $3 b$ also received support; both types of prior experience are positively associated with productivity. Hypothesis 4 received partial support, as only the interaction between a $\mathrm{PhD}$ from a top-ranked school and prior experience in the United States shows significant and negative coefficient.

The results of the multilevel mixed modeling analysis for the number of citations (the impact of research) are mostly consistent with the earlier reported findings on volume of publications. The key difference between the drivers of research volume and impact is the higher importance of organizational environment in producing impactful research. 
TABLE 2

Means, Standard Deviations, and Correlations

\begin{tabular}{|c|c|c|c|c|c|c|c|c|c|c|c|c|c|c|c|}
\hline & & $M$ & $S D$ & 1. & 2. & 3. & 4. & 5. & 6. & 7. & 8. & 9. & 10. & 11. & 12. \\
\hline 1. & $\begin{array}{l}\text { Log }(1+\text { Number of } \\
\text { Published Popers, } \\
\text { fractional, per year })\end{array}$ & 0.33 & 0.19 & 1.00 & & & & & & & & & & & \\
\hline 2. & $\begin{array}{l}\text { Log }(1+\text { Number of Citations, } \\
\text { fractional, adjusted by } \\
\text { lifespan) }\end{array}$ & 2.72 & 1.20 & $0.70^{*}$ & 1.00 & & & & & & & & & & \\
\hline 5 & Discipline area & 4.98 & 2.41 & $0.11^{*}$ & $0.12^{*}$ & $0.08^{*}$ & -0.05 & 1.00 & & & & & & & \\
\hline 6. & $\begin{array}{l}\text { PhD from top- } 10 \text { schools } \\
\quad(1=\text { yes })^{\alpha}\end{array}$ & 0.43 & 0.50 & $0.08^{*}$ & $0.10^{*}$ & -0.02 & -0.00 & -0.05 & 1.00 & & & & & & \\
\hline 7. & Impact factor of lst journal & 3.18 & 2.67 & -0.07 & $0.17^{*}$ & $-0.07^{*}$ & -0.04 & 0.05 & 0.01 & 1.00 & & & & & \\
\hline 8. & Time before lst publication & 1.74 & 4.30 & $-0.22^{*}$ & $-0.13^{*}$ & $0.13^{*}$ & 0.03 & -0.07 & -0.01 & -0.00 & 1.00 & & & & \\
\hline 11. & $\begin{array}{l}\text { Prior experience (number of } \\
\text { academic jobs) in the U.S. }\end{array}$ & 2.63 & 1.01 & $0.14^{*}$ & $0.19^{*}$ & $0.10^{*}$ & 0.01 & 0.02 & 0.01 & -0.04 & 0.05 & $-0.19^{*}$ & $0.22^{*}$ & 1.00 & \\
\hline 12. & $\begin{array}{l}\text { Prior experience (number of } \\
\text { academic jobs) outside } \\
\text { the U.S. }\end{array}$ & 0.11 & 0.36 & 0.07 & 0.06 & 0.02 & 0.00 & -0.00 & $-0.10^{*}$ & 0.03 & $0.13^{*}$ & $-0.09^{*}$ & 0.04 & $-0.12^{*}$ & 1.00 \\
\hline
\end{tabular}

$N=500$. Correlations marked with * are significant at least at the $10 \%$ level (two-tailed). Correlations with variables 4 and 6 are pointbiserial.

${ }^{\alpha}$ Correlations are corrected for scale coarseness as recommended in Aguinis, Pierce, and Culpepper (2009).

Both the coefficient for the rank of $\alpha \mathrm{PhD}$ and for the impact factor of a first journal publication are positive and significant. Fourteen percent of variance in the impact of research can be attributed to the average research-intensiveness of the organizational environment where academics spend their careers. Another difference is related to the interaction between the rank of $a \mathrm{PhD}$ and prior academic experience: For the impact of research, the interaction of a top-ranked $\mathrm{PhD}$ with experience outside the United States is negative and significant, while the interaction with experience in the United States is not. Results of the analysis for impact of research are presented in Table 4.

We concluded the analysis by looking at the relative strength of organizational- and individuallevel drivers of individual research performance and the amount of explained variation in outcome variables each of the levels of analysis provides. ${ }^{8}$ The summary of this analysis is presented in Table 5. Proactive strategies show strong complementarity, to

\footnotetext{
${ }^{8}$ Detailed results of this analysis are available from the authors upon request.
}

the extent that collaboration fully captures any variance explained by mobility. Taken separately, the organizational-level factors explain $6 \%$ of variance in volume and impact of publications, while the individual-level factors explain $29 \%$ variance in volume and in impact of publications. Together the organizational and the individual factors explain 37\% of variance in volume and $36 \%$ of variance in impact of research. The rank order of variables in terms of explained variance (based on the comparison of standardized effect sizes) is provided at the bottom of Table 5 .

\section{DISCUSSION}

In the competitive landscape of business education, research performance has become an increasingly important factor defining a business school's standing in the industrial hierarchy. We have provided general insights into the rules of the "publishor-perish" game by exploring research productivity drivers in the careers of academics employed by the top research-intensive business schools. A prior study by Aguinis et al. (2010) looked into the research 
TABLE 3

Results of MLM for Log (1+Total Number of Papers per Year, Adjusted by Coauthorship)

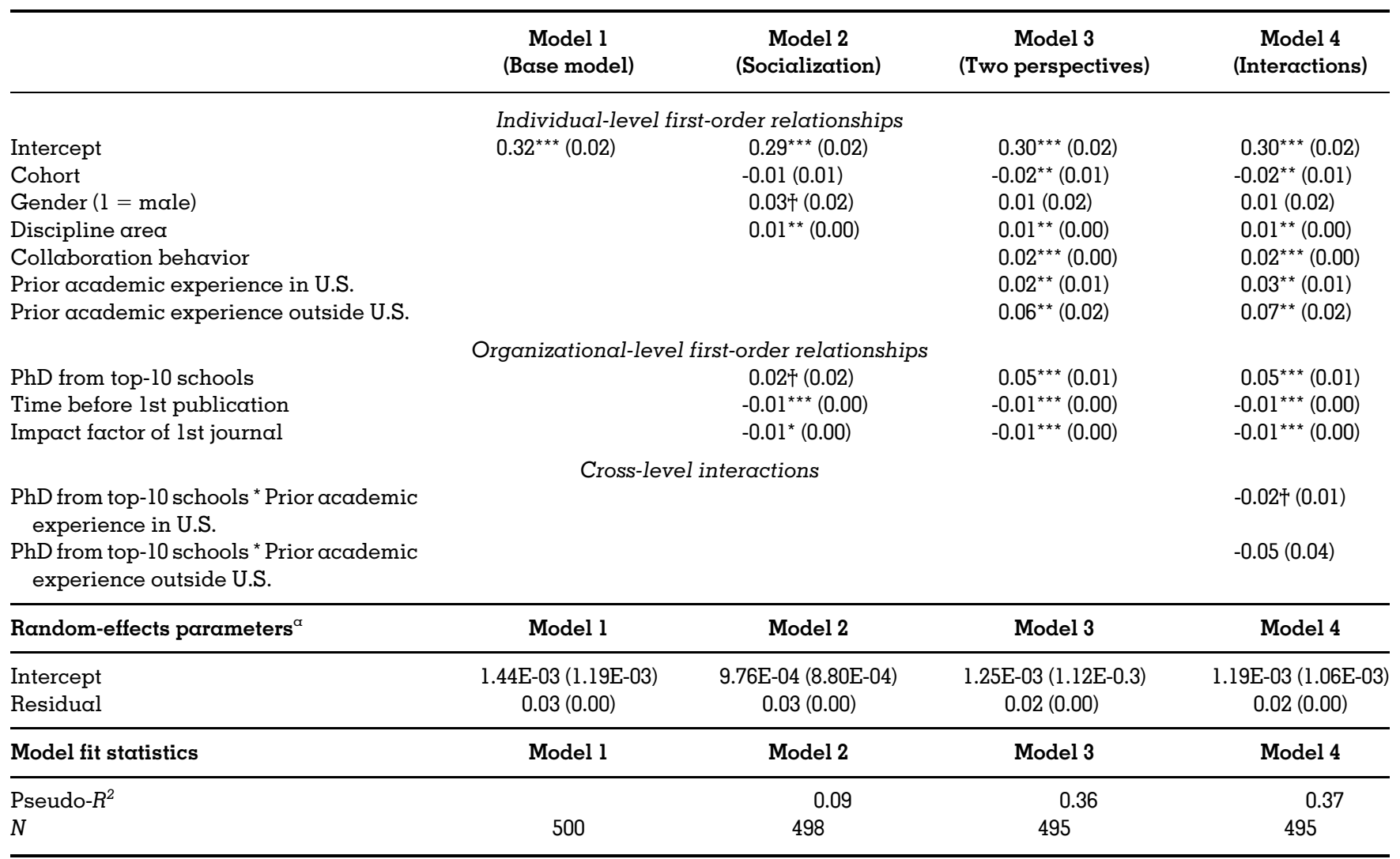

$N=500$ individuals (Level 1) in 11 groups (Level 2). Groups are based on weighted rank of all workplaces.

Significance levels are one-tailed for hypothesized relationships and two-tailed otherwise.

${ }^{* * *} p<0.001,{ }^{* *} p<0.01,{ }^{*} p<0.05$, † $p<0.1$

$\alpha$ This part of the table shows the variability of the multilevel model's intercept and slope due to group-level variance.

performance of journal editors and offered advice for these influential gatekeepers of the scientific field. In the same vein, our study sought to facilitate the research socialization of doctoral students, promote effective mentorship of junior faculty members, and enable successful selection of candidates for research-active faculty positions. This is particularly relevant to individuals and organizations who thus far have had less exposure to publishing in peer-reviewed journals. Understanding the underlying mechanisms behind research productivity might also help business schools to recognize competitive strategies employed by their rivals to boost faculty research performance.

The main objective of our study was to assess a comparative input of individual and organizational factors into the explanation of variance in research productivity. To achieve this we revisited the core conceptual building blocks of the multilevel model of research productivity. This foundational part of our work serves as a constructive replication of prior studies, such as McFadyen and colleagues (McFadyen \& Cannella, 2004; McFadyen et al., 2009; Seibert et al., 2014). Constructive replication ${ }^{9}$ uses populations and analytical techniques that are different from the initial study to test "the score and the limits of initial findings by seeing if they can be generalized to other populations, time periods, organizations, geographical areas, measurement instruments, contexts, and so on" (Hubbard, Vetter, \& Little, 1998: 244). We tested validity and generalizability of prior findings by using a different population of researchers and a more advanced methodological approach, which accounted for the nested structure of academic career data. Scholars argue that replications with extensions are fundamentally important to the development of organizational science (Hubbard et al., 1998; McKinley, 2010; Mezias \& Regnier, 2007;

\footnotetext{
${ }^{9}$ Also called differentiated replication or replication with extension.
} 
TABLE 4

Results of MLM for Log (1+ Number of Citations, Adjusted by Coauthorship and Paper Lifespan)

\begin{tabular}{|c|c|c|c|c|}
\hline & $\begin{array}{c}\text { Model l } \\
\text { (Base model) }\end{array}$ & $\begin{array}{c}\text { Model } 2 \\
\text { (Socialization) }\end{array}$ & $\begin{array}{c}\text { Model } 3 \\
\text { (Two perspectives) }\end{array}$ & $\begin{array}{c}\text { Model } 4 \\
\text { (Interactions) }\end{array}$ \\
\hline \multicolumn{5}{|c|}{ Individual-level first-order relationships } \\
\hline Cohort & & $0.03(0.05)$ & $-0.06(0.04)$ & $-0.05(0.04)$ \\
\hline Gender $(1=$ male $)$ & & $-0.04(0.14)$ & $-0.14(0.11)$ & $-0.13(0.11)$ \\
\hline Discipline area & & $0.06^{\star *}(0.02)$ & $0.05^{\star *}(0.02)$ & $0.06^{\star \star}(0.02)$ \\
\hline Prior academic experience outside U.S. & & & $0.21^{*}(0.12)$ & $0.39^{* *}(0.15)$ \\
\hline \multicolumn{5}{|c|}{ Organizational-level first-order relationships } \\
\hline $\mathrm{PhD}$ from top-10 schools & & $0.14 \mp(0.10)$ & $0.28^{* *}(0.09)$ & $0.27^{\star \star}(0.09)$ \\
\hline Time before lst publication & & $-0.03^{\star *}(0.01)$ & $-0.02^{*}(0.01)$ & $-0.02^{*}(0.01)$ \\
\hline Impact factor of lst journal & & $0.06^{\star * *}(0.02)$ & $0.05^{\star * *}(0.02)$ & $0.05^{\star *}(0.02)$ \\
\hline Random-effects parameters ${ }^{\alpha}$ & Model 1 & Model 2 & Model 3 & Model 4 \\
\hline Intercept & $0.21(0.17)$ & $0.15(0.12)$ & $0.23(0.16)$ & $0.20(0.15)$ \\
\hline Residual & $1.32(0.08)$ & $1.22(0.08)$ & $0.84(0.05)$ & $0.83(0.05)$ \\
\hline Model fit statistics & Model 1 & Model 2 & Model 3 & Model 4 \\
\hline Pseudo- $R^{2}$ & & 0.10 & 0.30 & 0.32 \\
\hline$N$ & 500 & 498 & 495 & 495 \\
\hline
\end{tabular}

$N=500$ individuals (Level l) in 11 groups (Level 2). Groups are based on weighted rank of all workplaces.

Significance levels are one-tailed for hypothesized relationships and two-tailed otherwise.

a This part of the table shows the variability of the multilevel model's intercept and slope due to group-level variance.

${ }^{\star * *} p<0.001,{ }^{* *} p<0.01,{ }^{*} p<0.05, \mp p<0.1$

Uncles \& Kwok, 2013). Replications ensure that Type 1 errors (erroneous rejections of the null hypothesis) do not "filter into textbooks to be taught as established truths" (Hubbard et al., 1998: 243). Constructive replications also contribute to higher theoretical coherence in organizational science by integrating conceptual "fragments" from prior studies into "streams of empirical research that would provide a source of continuity in the discipline" (McKinley, 2010: 57).

Conceptually, we embarked upon a journey in search of a middle ground between two streams of research on the individual performance of academic researchers. The findings of the study provide support to both perspectives and show their complementarity. The consensus created by our study helps translate the insights from the research on publishing productivity into the practice of managing academic researchers and developing a new cohort of doctoral students, thus bridging the "researchpractice gap" (McKinley, 2010).
The first perspective emphasized the path-dependent nature of academic careers and the overarching importance of organizational scripts in supporting research productivity (Bedeian et al., 2010; Williamson \& Cable, 2003; Zubieta, 2009), starting from earlycareer socialization in $\mathrm{PhD}$ schools. We found that the research-intensiveness of workplaces indeed has a strong positive connection to the volume and the scholarly impact of research. We also found that the graduates of the top research-intensive $\mathrm{PhD}$ schools are more likely to spend their careers in research-intensive schools. An important new insight was that the correlation between the research rank of PhDs and the average research rank of post$\mathrm{PhD}$ workplaces is not as high as to suggest fully deterministic career paths.

Looking at the quality of the first journal where an academic publishes work as another consequence of early-career socialization, we see that it is not related to the research-intensiveness of the chosen 
TABLE 5

Results of Standardized OLS Multiple Regression Analysis for Both Outcome Variables $(N=500)$

\begin{tabular}{|c|c|c|}
\hline & \multicolumn{2}{|c|}{ Outcome variables } \\
\hline Control variables (Base model) & $R_{\text {adj }}^{2}=0.02$ & $R_{\text {adj }}^{2}=0.01$ \\
\hline $\begin{array}{l}\text { Symbolic capital: } \\
\text { PhD from top-10 schools } \\
\text { Weighted research rank of all } \\
\quad \text { workplaces }\end{array}$ & $\begin{array}{l}\text { Organizational-level predictors } \\
\qquad \Delta \mathrm{R}_{\text {adj }}^{2}=0.02\end{array}$ & $\Delta R_{\text {adj }}^{2}=0.03$ \\
\hline $\begin{array}{l}\text { Intellectual capital: } \\
\text { IF of lst journal } \\
\text { Time before lst publication }\end{array}$ & $\Delta R_{\text {adj }}^{2}=0.05$ & $\Delta R_{\text {adj }}^{2}=0.04$ \\
\hline Organizational-level variables, total & $\Delta R_{\text {adj }}^{2}=0.06$ & $\Delta R_{\text {adj }}^{2}=0.06$ \\
\hline $\begin{array}{l}\text { All predictors } \\
\text { Rank order of predictors, from most to } \\
\text { least important }\end{array}$ & $\begin{array}{l}\qquad \Delta R^{2} \text { adj }=0.37 \\
\text { 1. Collaboration behavior } \\
\text { 2. Time before } 1^{\text {st }} \text { publication } \\
\text { 3. PhD from top-10 schools } \\
\text { 4. Weighted research rank of all workplaces } \\
\text { 5. IF of lst journal } \\
\text { 6. Prior academic experience outside U.S. } \\
\text { 7. Prior academic experience in U.S. }\end{array}$ & $\begin{array}{l}\qquad \Delta R_{\text {adj }}^{2}=0.36 \\
\text { 1. Collaboration behavior } \\
\text { 2. Weighted research rank of all workplaces } \\
\text { 3. PhD from top-10 schools } \\
\text { 4. Prior academic experience in U.S. } \\
\text { 5. IF of lst journal } \\
\text { 6. Prior academic experience outside U.S. } \\
\text { 7. Time before lst publication }\end{array}$ \\
\hline
\end{tabular}

Note. IF = impact factor.

${ }^{\alpha}$ Due to $\alpha$ certain degree of complementarity between variables, the sum of individually explained varionces does not add up to the total.

PhD school. We suggest that this might be due to the overarching role of $\mathrm{PhD}$ advisors in the early publishing choices of doctoral students (e.g., Williamson \& Cable, 2003). It has to be said, however, that while the impact factor of academics' first journal publications is positively related to the long-term impact of their research, it is negatively associated with the long-term volume of their research. This indicates a possible trade-off between the volume and the impact of research. The academics who started publishing in higher ranked journals may prefer visibility to number of publications throughout their careers, either because of high levels of aspirations acquired at their PhD schools, or because early visibility gives them access to research-intensive schools where the bar for the quality of journals in the faculty publication portfolio is set particularly high. A recent study by Seibert et al. (2014) provides evidence confirming this assumption. In a sample of 119 U.S. management professors, they found the research rank of a $\mathrm{PhD}$ to be positively associated with publications in top journals and negatively associated with publications in lower ranked journals.

The second perspective suggests that social capital, acquired through collaboration and mobility, is a major driver of research outputs in academia (e.g., He, Geng, \& Campbell-Hunt, 2009; McFadyen \& Cannella, 2004). Our study provides evidence for this assumption and estimates social capital to be a relatively stronger driver of productivity than socialization. Proactive behavior may, therefore, be instrumental in the careers of those academics who lack socialization in research-intensive environments. Because our measure of collaboration behavior includes both the size of a network and the strength of the ties in it, research-active academics have a reason to strive for a balance in the structure of their coauthorship ego-networks. When starting a new project, academics may consider the importance of tie strength before making a decision whether 
to work with one of their prior coauthors or to engage in a new collaboration. One potential consequence might be an increase in the size of coauthorship teams as researchers expand their networks without losing the support provided by their established research relationships. Given the complex nature of research activities and the traditionally autonomous approach to research in the field of social sciences (as contrasted with lab-based research in life sciences, e.g.), the task of managing larger teams of creative people may become a challenge. Findings from the research conducted into other creative industries indicate that collaboration on a larger scale is likely to produce extreme (either very good or very poor) outcomes (Taylor \& Greve, 2006). We suggest that studying this potential conundrum and the trade-off between the scope and the depth of collaboration in social sciences could become on interesting avenue for future research.

Academic mobility has increasingly become a focus of discussion among academic career researchers as another proactive strategy supporting research productivity (e.g., Cruz-Castro \& SanzMenendez, 2010; Richardson \& Zikic, 2007). Our study is the first to measure the importance of this strategy as a driver of research productivity. We found that mobility has a positive link to research performance, but the strength of this driver is low relative to the other antecedents, explaining only $4 \%$ of variance in impact and $3 \%$ of variance in volume of publications. This might be specific to the U.S. environment, which exhibits lower mobility (in particular, lower international mobility) than other geographical segments of the global business school industry. We encourage other scholars to test the assumptions of this study in non-U.S. settings to determine the boundary conditions of our theory.

In exploring the nuances of the interaction between organizational factors and individual behaviors, we found that mobility has a weaker relationship with performance for the graduates of top-ranked PhD schools. Specifically, for these graduates, mobility within the United States has a weaker link to the volume of research, while mobility outside the United States has a weaker link to the impact of research. To interpret these findings, we reflect upon the consequences of two distinct career strategies. The graduates of top-ranked U.S. schools who engage in mobility in the United States are likely to experience a downward trend in prestige, moving to lower ranked schools, as this is the most common career trajectory in this market (Miller et al., 2005). In these lower ranked schools, they are likely to have higher teaching loads, which will leave them less time to produce publications. At the same time, staying in the country will allow these academics to maintain relationships with their coauthors and to keep up with research conversations, which is crucial for producing impactful work. The graduates of top-ranked U.S. schools who decide to move abroad are usually hired for their research potential, as a part of non-U.S. schools strategy of increasing research output. As star assets, these academics are able to negotiate lower teaching loads and other research supports. This leads to research output comparable to their peers who did not expatriate. Relocation, however, brings them to the periphery of research conversations, and makes it more difficult to communicate with their U.S.-based coauthors. The flow of information from the industry center also becomes less abundant and is partially replaced by local information from the country of employment. Studies based on nonU.S. data, although highly relevant to the respective local market, are sometimes met with suspicion in the reviewing process (Meyer \& Boxenbaum, 2010), which may impede their access to the most visible research outlets. Therefore, the mobility strategy works as a compensatory mechanism for the graduates of lower ranked $\mathrm{PhD}$ schools but does not bring as much value, in terms of research productivity, to the graduates of top-ranked $\mathrm{PhD}$ schools.

Bringing these two perspectives together through a microfoundations lens, we see the development of research productivity in business schools in a familiar but more positive light. The initial choice of a high- or low-ranked school has a strong influence on research productivity by facilitating or hampering access to research-intensive environments. At the same time, the proactive accumulation of resources after graduation is also an important tool that can potentially balance out the situation for those who do not enjoy the advantages of initial anchoring in the top academic stratum. The data shows that the graduates of lower ranked $\mathrm{PhD}$ schools are more active in collaboration and in accumulating experience through mobility. Clearly there is more than one way to achieve success in academic publishing: All academics in our sample are tenured in research-intensive U.S. business schools where research performance is highly valued. The findings of this study advance the "new careers" literature, which emphasizes the duality of structure and agency in organizations (Dany et al., 2011; Duberley et al., 2006), by offering quantitative evidence to this predominantly qualitative stream of research. 


\section{A Note on the Generalizability of Findings}

Are these findings, based on a sample of academics employed by top research-intensive schools, useful for researchers located outside of the elite stratum of research universities? Faculty members in lower ranked schools have fewer resources and sometimes lack knowledge relative to academics in our sample, but they are increasingly expected to compete with their better placed peers for space in top peer-reviewed journals. Another research project undertaken by the authors of this paper revealed that in 2007-2012, academics from more than 2500 institutions worldwide published in the top- 160 journals listed in Thomson Reuters Journal Citation Reports. Recent studies by Aguinis and colleagues have provided evidence to the fact that the performance of knowledge workers is characterized by power law distribution, which has the property of scale invariance (Aguinis et al., 2016). This means that at any level of organizational productivity, there is a small number of high performers who contribute a majority of output. Indeed, while all academics in our sample are employed in top research-intensive schools, data shows that the majority of them publish less than one paper per year, and a small minority $(4 \%)$ publish between one and three papers annually. ${ }^{10}$ The same pattern of productivity should be present in other strata of the business school industry. Interestingly enough, Miller et al. (2005) also found a type of scale invariance in the patterns of academic careers, where the general pattern of mobility was similar for everyone, although the graduates of high-status institutions moved across workplaces that have a higher average level of prestige.

Our work here seeks to help researchers in becoming highly productive employees in their strata. Reflecting upon the mechanisms underlying our findings, we argue that the magnitude of found relationships should be even larger in lower strata schools. The faculty members in these schools have a lower stock of symbolic and intellectual capital. In the absence of these, social capital becomes a more important source of knowledge and support. At the same time, those academics who have had at least some exposure to highly research-intensive environments have a stronger advantage in publishing visible and more impactful research relative to their colleagues, most of whom have never been exposed

\footnotetext{
${ }^{10}$ These figures are weighted by the number of coauthors, so that, for instance, one paper written with two coauthors is counted as one third of the paper.
}

to the rules and incentives of the "publish-or-perish" culture. This is a "big fish in a small pond" effect: It is not the absolute amount of resources that matters, but rather individual standing relative to the peer group (i.e., colleagues in the same stratum). This is one reason why the MLM method was chosen for this study: It groups academics according to ministrata based on their level of exposure to research in their post-PhD careers, and adjusts the value of their capital (symbolic, intellectual, and social) by comparing it to the group-specific mean.

\section{Implications for the Business School Industry}

We demonstrate the significant role that human agency plays in achieving superior performance in knowledge-intensive industries. This is on important insight for both aspiring and established academics. Although the research on academic industry characteristics reveals increasing competition for the space in top-tier journals (Certo et al., 2010) and an overwhelming pressure to publish in these scholarly outlets (Day, 2011; Miller, Taylor, \& Bedeian, 2011), the traditional view of scientific productivity provides limited opportunities for those who embark upon academic careers from lower strata. Our findings offer encouragement to business schools that are currently placed outside the top stratum, because they demonstrate the long-term consequences of alternative strategies of resource accumulation, thus facilitating everyday decision making on the part of research-active faculty members.

The findings also inform the decision making of business-school hiring committees and contribute to lower information asymmetry in the candidate screening process. First, the configuration of a coauthorship network, both in terms of its scope and in terms of the strength of its collaborations between coauthors, should be considered a key factor when assessing the potential productivity of applicants. Second, separate exploration of factors associated with the volume and the impact of research reveals the nuances of the microfoundations behind research performance in business schools. The volume of research is largely driven by proactive behaviors; organizational factors mainly influence this dimension of performance by enabling early publishing at the beginning of a researcher's career. The impact of research is more dependent on organizational factors; placement in the top strata of research-intensive business schools facilitates access to most visible journals (Crane, 1967) and the 
ability to disseminate knowledge among a broader academic audience. Hiring committees of business schools should, therefore, consider different dimensions of an applicant's career history, dependent on their strategic goals. Third, the nuances of relationships between mobility and research output, especially pronounced for graduates of topranked $\mathrm{PhD}$ programs, should be considered when assessing the potential productivity of international applicants whose initial collaboration networks are derived from high-status institutions located abroad.

\section{Implications for Management Education}

In the highly competitive environment of today's knowledge-intensive industries, it is important to teach our students the value of proactive behavior in knowledge workers' careers. This study provides some empirical evidence that can be applied to the practice of preparing business-school PhD graduates for their future careers. By exploring U.S. academics' careers, we can clearly see that the achievements of these faculty members did not arise predominantly just because they were in the right place in the industry at the right time. Proactive strategies of networking and mobility between organizations provided these actors with access to social capital and made them more productive scholars.

While a lot of attention has been given to the education of undergraduate and MBA students (e.g., Bedwell, Fiore, \& Salas, 2014; Bevelander \& Page, 2011; Eisenberg et al., 2013), doctoral students seem to exist on the periphery of business schools (for some exceptions, see e.g., Baker \& Lattuca, 2010; Moss Breen \& Barbuto Jr., 2010). This is arguably because their numbers are much smaller than those in other programs. At the same time, the education of doctoral students often requires a deeper engagement from faculty members and represents a more long-term commitment than the education of MBA and undergraduate students (Ashford, 1996). Moreover, doctoral students are just one step away from becoming faculty members themselves, and thus, in our opinion, their education has to include all elements of socialization into professional and organizational life, such as "values, expected behaviors, and social knowledge" (Cable et al., 2013: 2).

It is not enough to train doctoral students in methodology and best research practices. Knowledge of the "rules of the game" existing in the business education industry also has to be transferred if the graduates of $\mathrm{PhD}$ programs are to find their place in the academic world. Currently, the transfer of this knowledge depends on the goodwill of doctoral supervisors who decide to share insights from their idiosyncratic academic experiences. Organizational incentives currently existing in business schools do not reward faculty members for their quality of doctoral teaching, in contrast with other programs where teaching performance is regularly monitored, evaluated, and sometimes marked by "Best Professor" awards (Ashford, 1996). Our work here highlights general trends in behaviors that are associated with higher research productivity in business schools, with the aim of educating doctoral students on the rules of the game in our field. As any such rules, these represent broad guidelines that have to be tempered by individual circumstances and the preferences of each $\mathrm{PhD}$ graduate.

Both professional socialization and collaboration behavior have an impact on the development of research productivity. This suggests the need for a balance between the anchoring of $\alpha \mathrm{PhD}$ student in an immediate institutional environment and the openness to external academic community. We see this as a stepwise approach to training and socialization that requires a coordinated institutional intervention. First, newly admitted PhD students should get to know their own institution, socialize with local faculty, and benefit from their expertise. In some educational systems, for example, in Europe, doctoral studies have had a semiautonomous nature, characterized by infrequent interaction between student and mentoring faculty (Hakala, 2009). Where this ethos persists, $\mathrm{PhD}$ directors and individual supervisors have to take a stance of encouraging the active participation of doctoral students in researchfocused initiatives that could result in better professional socialization.

In the second step, once PhD students have acquired some research skills and gained more clarity on their topics of interest, they would benefit from reaching outward and establishing professional relationships with academic peers beyond the boundaries of their $\mathrm{PhD}$ schools. Our use of the word "relationships" instead of "networks" is deliberate: Our research shows the importance of strong ties, that is, repeated collaborations built on mutual trust and understanding. Rather than teaching $\mathrm{PhD}$ students how to build networks that help achieving short-term goals, such as finding a job (e.g., de Janasz \& Forret, 2008), we need to teach them how to network to improve their long-term work performance (Judge et al., 2012). This type of networking 
requires understanding of a potential network partner and deliberate efforts to find or create fit between oneself and a potential collaborator.

Although many scholars admit that some of their most productive collaborations started in a serendipitous way (e.g., Dutton, Bartunek, \& Gersick, 1996), we argue that investing effort in the search for potential research partners might enable earlycareer researchers to move beyond the realm of lucky chances. Institutional policies that support participation in international conferences and doctoral consortiums would facilitate this effort. Student visits with the purpose of research training, where such training takes place within another business school, is another way to support $\mathrm{PhD}$ students' socialization and collaboration.

Early-stage doctoral students might feel too insecure to seek advice from academics other than their main supervisors. Taking risks and approaching seasoned scholars with research conversations may be uncomfortable while one's underdeveloped ideas are dissected by an experienced hand, but this risk may pay off later. First, external references are often necessary for a job application. Second, having external coauthors facilitates $\mathrm{PhD}$ graduates' early-career transition from student to independent researcher by engaging them in projects unrelated to their supervisor. Strong relationships with coauthors are an important source of research support, but building relationships takes time. The earlier one starts to reach out to external academic community, the more time one has to test which potential collaborators are a good professional and personal match with one's ideas and personality.

The insights from our study may also be instrumental for academic administrators responsible for the management of doctoral programs (e.g., $\mathrm{PhD}$ directors), in particular for those located outside the traditional core of research-intensive business schools. With the expansion of the business education sector, the population of these decision-makers has steadily increased, and not all of them have had firsthand experience with the blend of "publish-orperish" and "publication in the most visible journals" ethos that is currently on the rise (Adler, 2014). If doctoral programs worldwide are to produce research-active graduates who are capable of publishing impactful research, mentors need to realize the importance of exposing their students to researchintensive environments. Where an institution lacks local resources to create such environments, research visits or participation in research seminars led by invited scholars may partly fill the gap. Ideally, the preference should be given to visiting faculty who have interest in working with $\mathrm{PhD}$ students.

The characteristics of academics' first scholarly publications play an important role in their academic productivity development, and there are great challenges involved in finding a compromise between publishing early and publishing in a high-quality journal. Consequently, we believe that doctoral programs should put an emphasis on publishing-support systems that would help inexperienced researchers tailor their first publications for scholarly outlets that would fit their future career and research strategies. In particular, the culture of friendly reviews by one's faculty (in addition to feedback from a primary supervisor) needs to be promoted. High-quality copy-editing should also be made available to all doctoral students, especially those coming from non-English speaking backgrounds.

\section{Limitations and Reflections on the Need for Pluralism}

In discussing publication outcomes here, we have assumed that publishing in higher ranked journals (those with higher impact factors) is desirable for faculty members, due to the visibility of these outlets, which is linked to the probability of a paper being read and cited (Judge et al., 2007). There are, however, several arguments against the simplicity of this approach to the choice of target journals. First, research shows that not all the papers published in top journals are necessarily of higher quality than those published in the journals with lower impact factors (Singh, Haddad, \& Chow, 2007). Second, the rankings of journals used in business schools have significant methodological flaws (e.g., Adler \& Harzing, 2009; Ozbilgin, 2009) and fail to equally represent all disciplines, research fields, and stakeholder groups. Third, the established format of top journals may be less friendly to radically novel and original research (in recognition of this fact, the Academy of Management has recently launched its Academy of Management Discoveries journal), or to studies conducted in different research traditions (e.g., Pratt, 2008).

Ultimately, it is important for researchers to find the audience interested in what they have to say, rather than solely to strive to publish in the journal with the highest possible rank. The presence of a vibrant research community around a particular topic may bring higher visibility and create $a$ 
greater scholarly impact than a highly cited journal covering topics of general interest. Given that we do not compromise on the quality of our studies, having an open mind about the outlets through which we communicate our ideas may be beneficial for keeping our field refreshingly pluralistic.

\section{Directions for Future Research}

Our study took a retrospective view on academic careers with the objective of bridging two distinct conceptual perspectives and comparing their contribution to the explanation of research outcomes. A further study using longitudinal data may provide deeper insights into step-by-step trajectories of research productivity development and possible critical junctures that academics face along the way. A conceptual starting point for such a study would be to take our work and blend this with the conceptual insights of path-dependency literature (Sydow, Schreyogg, \& Koch, 2009). Although it is unlikely that career trajectories could be replicated, such a study could provide insights into decision making of academics and the consequences of different choices at a particular stage of a researcher's career. The research design of such a study would have some challenges.

First, in thinking about academic careers, two dimensions of research performance are of particular importance. An academic has to achieve visibility in the scholarly community by the regular publication of research. This visibility is measured by the volume of research output, which may be relatively easily allocated to a year of publication. There is also a need to understand whether an academic's publication output has an impact on science and practice. Most studies using bibliometric data choose the number of citations as the most validated measure. Due to the nature of a citation process, that is that the citations to one's papers are accumulated throughout the entire career, it is more difficult to allocate these to a particular year without an analysis of citation history for each paper. Second, there is a challenge in collecting enough data to have a panel of sufficient size while keeping both organizational and individual predictors in the model, as suggested by the multilevel framework developed here. Given that the data for variables come from multiple sources and need a fair amount of manual processing, this may be a task for a large research team or one that would require the development of programs that enable automatic combination of text-based CVs and multiple databases.

\section{REFERENCES}

Adler, N. J., \& Harzing, A. W. 2009. When knowledge wins: Transcending the sense and nonsense of academic rankings. Academy of Management Learning \& Education, 8: 72-95.

Adler, P. 2014. Some thoughts on our internationalization. AcadeMY News, 1(2): 3.

Aguinis, H., de Bruin, G. P., Cunningham, D., Hall, N. L., Culpepper, S. A., \& Gottfredson, R. K. 2010. What does not kill you (sometimes) makes you stronger: Productivity fluctuations of journal editors. Academy of Management Learning \& Education, 9: 683-695.

Aguinis, H., O’Boyle, E., Jr., Gonzalez-Mule, E., \& Joo, H. 2016. Cumulative advantage: Conductors and insulators of heavy-tailed productivity distributions and productivity stars. Personnel Psychology, 69: 3-66.

Aguinis, H., Pierce, C. A., \& Culpepper, S. A. 2009. Scale coarseness as a methodological artifact: Correcting correlation coefficients attenuated from using coarse scales. Organizational Research Methods, 12: 623-652.

Albrecht, C., Thompson, J. A., \& Hoopes, J. L. 2011. Productivity and prestige in business ethics research: a report and commentary on the state of the field. Business \& Society, 50: 580-606.

Ashford, S. J. 1996. Working with doctoral students: Reflections on doctoral work past and present. In P. J. Frost \& M. S. Taylor (Eds.) Rhythms of academic life: 153-157. London: Sage.

Ashkanasy, N. M. 2010. Publishing today is more difficult than ever. Journal of Organizational Behavior, 31: 1-3.

Baker, V. L., \& Lattuca, L. R. 2010. Developmental networks and learning: Toward an interdisciplinary perspective on identity development during doctoral study. Studies in Higher Education, 35: 807-827.

Barney, J., \& Felin, T. 2013. What are microfoundations? The Academy of Management Perspectives, 27: 138-155.

Baruch, Y., \& Hall, D. T. 2004. The academic career: A model for future careers in other sectors? Journal of Vocational Behavior, 64: 241-262.

Bedeian, A. G., Cavazos, D. E., Hunt, J. G., \& Jauch, L. R. 2010. Doctoral degree prestige and the academic marketplace: $A$ study of career mobility within the management discipline. Academy of Management Learning \& Education, 9: 11-25.

Bedwell, W. L., Fiore, S. M., \& Salas, E. 2014. Developing the future workforce: An approach for integrating interpersonal skills into the MBA classroom. Academy of Management Learning \& Education, 13: 171-186.

Bevelander, D., \& Page, M. J. 2011. Ms.Trust: Gender, networks and trust-implications for management and education. Academy of Management Learning \& Education, 10: 623-642.

Bliese, P. D. 2002. Multilevel random coefficient modeling in organizational research: Examples using SAS and S-PLUS. In F. Drasgow \& N. Schmitt (Eds.), Measuring and analyzing behavior in organizations: Advances in measurement and data analysis: 401-445. San Francisco: Jossey-Bass.

Bonnal, L., \& Giret, J. F. 2009. La stabilisation des jeunes docteurs sur le marché de l'emploi académique. Revue d'Economie Politique, 119: 373-400. 
Boyd, B. K., Finkelstein, S., \& Gove, S. 2005. How advanced is the strategy paradigm? The role of particularism and universalism in shaping research outcomes. Strategic Management Journal, 26: 841-854.

Bozeman, B., \& Gaughan, M. 2011. How do men and women differ in research collaborations? An analysis of the collaborative motives and strategies of academic researchers. Research Policy, 40: 1393-1402.

Brass, D. J., Galaskiewicz, J., Greve, H. R., \& Tsai, W. 2004. Taking stock of networks and organizations: A multilevel perspective. Academy of Management Journal, 47: 795-817.

Breugst, N., Patzelt, H., Shepherd, D. A., \& Aguinis, H. 2012. Relationship conflict improves team performance assessment accuracy: Evidence from a multilevel study. Academy of Management Learning \& Education, 11: 187-206.

Burris, V. 2004. The academic caste system: Prestige hierarchies in $\mathrm{PhD}$ exchange networks. American Sociological Review, 69: 239-264.

Buchmueller, T. C., Dominitz, J., \& Hansen, W. L. 1999. Graduate training and the early career productivity of $\mathrm{PhD}$ economists. Economics of Education Review, 18: 65-77.

Cable, D. M., Gino, F., \& Staats, B. R. 2013. Breaking them or eliciting their best? Reframing socialization around newcomers' authentic self-expression. Administrative Science Quarterly, 58: 1-36.

Callie, T. M., \& Cheslock, J. J. 2008. Hiring and compensation practices of business school deans. The Review of Higher Education, 32: 25-49.

Caplow, T., \& McGee, R. J. 2001. The academic marketplace. London, UK: Transaction Publishers.

Carayol, N., \& Matt, M. 2006. Individual and collective determinants of academic scientists' productivity. Information Economics and Policy, 18: 55-72.

Certo, S. T., Sirmon, D. G., \& Brymer, R. A. 2010. Competition and scholarly productivity in management: investigating changes in scholarship from 1988 to 2008. Academy of Management Learning \& Education, 9: 591-606.

Chan, K. C., Chen, C. R., \& Fung, H.-G. 2009. Pedigree or placement? An analysis of research productivity in finance. Financial Review, 44: 87-111.

Clemente, F., \& Sturgis, R. B. 1974. Quality of department of doctoral training and research productivity. Sociology of Education, 47: 287-299.

Coff, R., \& Kryscynski, D. 2011. Drilling for micro-foundations of human capital-based competitive advantages. Journal of Management, 37: 1429-1443.

Colquitt, J. A., Scott, B. A., \& Le Pine, J. A. 2007. Trust, trustworthiness, and trust propensity: A meta-analytic test of their unique relationships with risk taking and job performance. The Journal of Applied Psychology, 92: 909-927.

Crane, D. 1965. Scientists at major and minor universities: A study of productivity and recognition. American Sociological Review, 30: 699-714.

Crane, D. 1967. The gatekeepers of science: Some factors affecting the selection of articles for scientific journals. The American Sociologist, 2: 195-201.
Cruz-Castro, L., \& Sanz-Menendez, L. 2010. Mobility versus job stability: Assessing tenure and productivity outcomes. Research Policy, 39: 27-38.

D’Aveni, R. A. 1996. A multiple-constituency, status-based approach to interorganizational mobility of faculty and input-output competition among top business schools. Organization Science, 7: 166-189.

Dalal, D. K., \& Zickar, M. J. 2012. Some common myths about centering predictor variables in moderated multiple regression and polynomial regression. Organizational Research Methods, 15: 339-362.

Dany, F. 2003. 'Free actors' and organizations: Critical remarks about the new career literature, based on French insights. International Journal of Human Resource Management, 14: 821-838.

Dany, F., Louvel, S., \& Valette, A. 2011. Academic careers: The limits of the 'boundaryless approach' and the power of promotion scripts. Human Relations, 64: 971-996.

Day, N. E. 2011. The silent majority: Manuscript rejection and its impact on scholars. Academy of Management Learning \& Education, 10: 704-718.

de Janasz, S. C., \& Forret, M. L. 2008. Learning the art of networking: A critical skill for enhancing social capital and career success. Journal of Management Education, 32: 629-650.

Dietz, J. S., \& Bozeman, B. 2005. Academic careers, patents, and productivity: Industry experience as scientific and technical human capital. Research Policy, 34: 349-367.

Dokko, G., Wilk, S. L., \& Rothbard, N. P. 2009. Unpacking prior experience: How career history affects job performance. Organization Science, 20: 51-68.

Duberley, J., Cohen, L., \& Mallon, M. 2006. Constructing scientific careers: Change, continuity and context. Organization Studies, 27: 1131-115l.

Durand, R., \& McGuire, J. 2005. Legitimating agencies in the face of selection: The case of AACSB. Organization Studies, 26: 165-196.

Dutton, J. E., Bartunek, J. M., \& Gersick, C. J. G. 1996. Growing a personal, professional collaboration. In P. J. Frost \& M. S. Taylor (Eds.), Rhythms of academic life: 239-247. London: Sage.

Eisenberg, J., et al. 2013. Can business schools make students culturally competent? Effects of cross-cultural management courses on cultural intelligence. Academy of Management Learning \& Education, 12: 603-621.

Epley, N., \& Kruger, J. 2005. When what you type isn't what they read: The perseverance of stereotypes and expectancies over e-mail. Journal of Experimental Social Psychology, 41: 414-422.

Freeman, R. B., Ganguli, I., \& Murciano-Goroff, R. 2014. Why and wherefore of increased scientific collaboration. NBER Working Paper \#19819.

Gonzalez-Brambila, C. N., Veloso, F. M., \& Krackhardt, D. 2013. The impact of network embeddedness on research output. Research Policy, 42: 1555-1567.

Hakala, J. 2009. Socialization of junior researchers in new academic research environments: Two case studies from Finland. Studies in Higher Education, 34: 501-516. 
Hall, B. H., Mairesse, J., \& Turner, L. 2007. Identifying, age, cohort \& period effects in scientific research productivity: Discussion and illustration using simulated and actual data on French physicists. Economics of Innovation and New Technology, 16: 159-177.

Hamilton, B. H., \& Nickerson, J. A. 2003. Correcting for endogeneity in strategic management research. Strategic Organization, 1: 51-78.

Hasselback, J. R. 2014. Faculty Directories. Retrieved from http:// www.jrhasselback.com/FacDir.html.

He, Z.-L., Geng, X.-S., \& Campbell-Hunt, C. 2009. Research collaboration and research output: A longitudinal study of 65 biomedical scientists in a New Zealand university. Research Policy, 38: 306-317.

Hirschi, A., Freund, P. A., \& Herrmann, A. 2014. The career engagement scale: Development and validation of a measure of proactive career behaviors. Journal of Career Assessment, 22: $575-594$.

Horta, H., Veloso, F. M., \& Grediaga, R. 2010. Navel gazing: Academic inbreeding and scientific productivity. Management Science, 56: 414-429.

Hubbard, R., Vetter, D. E., \& Little, E. L. 1998. Replication in strategic management: Scientific testing for validity, generalizability, and usefulness. Strategic Management Journal, 19: 243-254.

Huisman, J., de Weert, E., \& Bartelse, J. 2002. Academic careers from a European perspective-The declining desirability of the faculty position. The Journal of Higher Education, 73: $141-160$.

Jepsen, D. M., et al. 2014. International academic careers: Personal reflections. International Journal of Human Resource Management, 25: 1309-1326.

Jones, O., \& Gatrell, C. 2014. Editorial: The future of writing and reviewing for IJMR. International Journal of Management Reviews, 16: 249-264.

Judge, T. A., Cable, D. M., Colbert, A. E., \& Rynes, S. L. 2007. What causes a management article to be cited-Article, author, or journal? Academy of Management Journal, 50: 491-506.

Judge, W. Q., Weber, T., \& Muller-Kahle, M. I. 2012. What are the correlates of interdisciplinary research impact? The case of corporate governance research. Academy of Management Learning \& Education, 11: 82-98.

Kruger, J., Epley, N., Parker, J., \& Ng, Z.-W. 2005. Egocentrism over e-mail: Can we communicate as well as we think? Journal of Personality and Social Psychology, 89: 925-936.

Lee, R. 2009. Social capital and business and management: Setting a research agenda. International Journal of Management Reviews, 11: 247-273.

Li, S., \& Seale, C. 2008. Acquiring a sociological identity: An observational study of a PhD project. Sociology, 42: 987-1002.

Linton, J. D. 2012. Business school research and rankings: Where do the schools really stand? Technovation, 32: 1-5.

Long, J. S., \& McGinnis, R. 1981. Organizational context and scientific productivity. American Sociological Review, 46: 422-442.

Long, R. G., Bowers, W. P., Barnett, T., \& White, M. C. 1998. Research productivity of graduates in management: Effects of academic origin and academic affiliation. Academy of Management Journal, 41: 704-714.

Mangematin, V., \& Baden-Fuller, C. 2008. Global contests in the production of business knowledge: Regional centres and individual business schools. Long Range Planning, 41: 117-139.

McFadyen, M. A., \& Cannella, A. A., Jr. 2004. Social capital and knowledge creation: Diminishing returns of the number and strength of exchange relations. Academy of Management Journal, 47: 735-746.

McFadyen, M. A., Semadeni, M., \& Cannella, A. A., Jr. 2009. Value of strong ties to disconnected others: Examining knowledge creation in biomedicine. Organization Science, 20: 552-564.

McKinley, W. 2010. Organizational theory development: Displacement of ends? Organization Studies, 31: 47-68.

Meyer, R. E., \& Boxenbaum, E. 2010. Exploring European-ness in organization research. Organization Studies, 31: 737-755.

Mezias, S. J., \& Regnier, M. O. 2007. Walking the walk as well as talking the talk: Replication and the normal science paradigm in strategic management research. Strategic Organization, 5: 283-296.

Miller, A. N., Taylor, S. G., \& Bedeian, A. G. 2011. Publish or perish: Academic life as management faculty live it. Career Development International, 16: 422-445.

Miller, C. C., Glick, W. H., \& Cardinal, L. B. 2005. The allocation of prestigious positions in organizational science: Accumulative advantage, sponsored mobility, and contest mobility. Journal of Organizational Behavior, 26: 489-516.

Moss Breen, J. A., \& Barbuto, J. E., Jr. 2010. Doctoral advising, research productivity and the academic balancing act: Insights from Michael A. Hitt, Edwin A. Locke, Fred Luthans, Lyman W. Porter, and Anne Tsui. Organizational Management Journal, 7: 182-191.

Ng, T. W. H., Sorensen, K. L., Eby, L. T., \& Feldman, D. C. 2007. Determinants of job mobility: A theoretical integration and extension. Journal of Occupational and Organizational Psychology, 80: 363-386.

Ozbilgin, M. 2009. From journal rankings to making sense of the world. Academy of Management Learning \& Education, 8: 113-121.

Payne, G. T., Moore, C. B., Griffis, S. E., \& Autry, C. W. 2011. Multilevel challenges and opportunities in social capital research. Journal of Management, 37: 491-520.

Ployhart, R. E., \& Moliterno, T. P. 2011. Emergence of the human capital resource: A multilevel model. Academy of Management Review, 36: 127-150.

Podsakoff, P. M., MacKenzie, S. B., Podsakoff, N. P., \& Bachrach, D. G. 2008. Scholarly influence in the field of management: A bibliometric analysis of the determinants of university and author impact in the management literature in the past quarter century. Journal of Management, 34: 641-720.

Pratt, M. G. 2008. Fitting oval pegs into round holes. Tensions in evaluating and publishing qualitative research in top-tier North American journals. Organizational Research Methods, 11: 481-509.

Richardson, J., \& McKenna, S. 2003. International experience and academic careers: What do academics have to say? Personnel Review, 32: 774-795. 
Richardson, J., \& Zikic, J. 2007. The dorker side of international academic career. Career Development International, 12: 164-186.

Sabatier, M., Carrere, M., \& Mangematin, V. 2006. Profiles of academic activities and careers: Does gender matter? An analysis based on French life scientist CVs. The Journal of Technology Transfer, 31: 311-324.

Seibert, S. E., Crant, J. M., \& Kraimer, M. L. 1999. Proactive personality and career success. The Journal of Applied Psychology, 84: 416-427.

Seibert, S. E., Kacmar, K. M., Kraimer, M. L., Downes, P. E., \& Noble, D. In press. The role of research strategies and professional networks in management scholars' productivity. Journal of Management, 10.1177/0149206314546196.

Singh, G., Haddad, K. M., \& Chow, C. 2007. Are articles in "top" management journals necessarily of higher quality? Journal of Management Inquiry, 16: 319-331.

Smith, J. S., Fox, G. L., Park, S.-H., \& Lee, L. 2008. Institutional antecedents to research productivity in operations: The US perspective. International Journal of Operations \& Production Management, 28: 7-26.

Sousa, C. A. A., de Nijs, W. F., \& Hendricks, P. H. J. 2010. Secrets of the beehive: Performance management in university research organizations. Human Relations, 63: 1439-1460.

Stephan, P. E., \& Levin, S. G. 1991. Inequality in scientific performance: Adjustment for attribution and journal impact. Social Studies of Science, 21: 351-368.

Stephan, P. E. 1996. The economics of science. Journal of Economic Literature, 34: 1199-1235.

Stuart, T. E., \& Ding, W. W. 2006. When do scientists become entrepreneurs? The social structural antecedents of commercial activity in the academic life sciences. American Journal of Sociology, 112: 97-144.
Sydow, J., Schreyogg, G., \& Koch, J. 2009. Organizational path dependence: Opening the black box. Academy of Management Review, 34: 689-709.

Taber, B. J., \& Blankemeyer, M. 2015. Future work self and career adaptability in the prediction of proactive career behaviors. Journal of Vocational Behavior, 86: 20-27.

Taylor, A., \& Greve, H. 2006. Superman or the Fantastic Four? Knowledge combination and experience in innovative teams. Academy of Management Journal, 49: 723-740.

Thomson Reuters 2008. Using bibiliometrics: A guide to evaluating research performance using citation data. White paper. Retrieved from http://thomsonreuters.com/products/ip-science/ 04_030/using-bibliometrics-a-guide-to-evaluating-researchperformance-with-citation-data.pdf.

Uncles, M. D., \& Kwok, S. 2013. Designing research with in-built differentiated replication. Journal of Business Research, 66: 1398-1405.

Vaara, E., \& Faÿ, E. 2011. Can a Bourdieusian perspective aid analysis of MBA education? Academy of Management Learning \& Education, 10: 27-39.

Vasileiadou, E., \& Vliegenthart, R. 2009. Research productivity in the era of the internet revisited. Research Policy, 38: 1260-1268.

White, C. S., James, K., Burke, L. A., \& Allen, R. S. 2011. What makes a "research star"? Factors influencing the research productivity of business faculty. International Journal of Productivity and Performance Management, 61: 584-602.

Williamson, I. O., \& Cable, D. M. 2003. Predicting early career research productivity: The case of management faculty. Journal of Organizational Behavior, 24: 25-44.

Zubieta, A. F. 2009. Recognition and weak ties: Is there a positive effect of postdoctoral position on academic performance and career development? Research Evaluation, 18: $105-115$.

Peter McNamara is currently the head of School of Business and professor of management at Maynooth University. He earned his PhD in Strategic Management from City University (London), Cass Business School. His research explores the processes and performance consequences of both collaboration and innovation (including R\&D and business models).

Olga Ryazanova is a lecturer of management in the School of Business at Maynooth University. She earned her PhD in Strategic Management from University College Dublin (Ireland). Her research focuses on microfoundations of firm behavior in knowledge-intensive industries, i.e., the individual and group-level processes that influence organizational decision making and outcomes. 
Copyright of Academy of Management Learning \& Education is the property of Academy of Management and its content may not be copied or emailed to multiple sites or posted to a

listserv without the copyright holder's express written permission. However, users may print, download, or email articles for individual use. 